This item was submitted to Loughborough's Research Repository by the author.

Items in Figshare are protected by copyright, with all rights reserved, unless otherwise indicated.

\title{
Cyberbullying at work: Understanding the influence of technology
}

PLEASE CITE THE PUBLISHED VERSION

https://doi.org/10.1007/978-981-10-5334-4_8-1

PUBLISHER

(C) Springer

VERSION

AM (Accepted Manuscript)

PUBLISHER STATEMENT

This chapter was accepted for publication in the book Concepts, Approaches and Methods and the definitive published version is available at https://doi.org/10.1007/978-981-10-5334-4_8-1

\section{LICENCE}

CC BY-NC-ND 4.0

\section{REPOSITORY RECORD}

Farley, Samuel, lain Coyne, and Premilla D'Cruz. 2019. "Cyberbullying at Work: Understanding the Influence of Technology". figshare. https://hdl.handle.net/2134/27558. 
Chapter Title: Cyberbullying at work: Understanding the influence of technology

\title{
Authors
}

Samuel Farley, University of Sheffield, Sheffield, UK. Email: s.j.farley@sheffield.ac.uk Iain Coyne, University of Loughborough, Loughborough, UK. Email: i.j.coyne@lboro.ac.uk

Premilla D’Cruz, Indian Institute of Management Ahmedabad, India. Email: pdcruz@iima.ac.in

\begin{abstract}
We exist at a time when technology has revolutionised the way people work. It is now just as easy to communicate electronically with colleagues thousands of miles away as it is with a coworker in the same building. While there are many advantages of information and communication technologies (ICTs), workplace cyberbullying channeled through ICTs illustrates the potential drawbacks of such technologies. The current chapter examines the limited, yet developing research on workplace cyberbullying. First, we discuss the criteria used to define workplace cyberbullying and the behaviours that encompass it. Second, we present current empirical findings, including research on the actors involved in the process and the antecedents, prevalence and impact of workplace cyberbullying. Finally, we discuss theoretical perspectives on why workplace cyberbullying occurs, highlight the emerging focus on the work context and present some suggestions for future research in this area.
\end{abstract}

Keywords: workplace cyberbullying, cyber harassment, computer-mediated communication (CMC), workplace technology, virtual abuse, online mistreatment, electronic bullying, digital workplaces, virtual workplaces, anonymity, information and communication technologies (ICTs), cyberaggression, internet, digital footprint

\section{Index terms}

Social media

Traditional bullying

Offline bullying

Supervisors 
Managers

Organisational outsiders

Customers

Online labour markets

Immateriality

Monitoring

Surveillance

Power

Harm

Intent

Repetition

Persistence

Phone

Picture

Video

Photo

Text message

Trolling

Quasi-perpetrators

Cyber stalking

Interventions

Youth

Adolescent

Children

School bullying

Email

Blog

Post

Voicemail

Face-to-face bullying

Definition

Audience

Private

Public

Access

Virus

Gender

Prevalence

Impact 
Organisations

Targets

Perpetrators

Victims

Bystanders 


\section{Introduction}

The jobs that people perform, as well as their working habits have changed dramatically in the past 40 years. In developing economies, technology has facilitated efficiencies in agriculture, manufacturing and the service sector, whilst also creating new forms of employment, such as call centre work, which has become an important source of income for employees in India and the Philippines. In western countries, trends have shown a gradual decline in the manufacturing sector coupled with growth in the knowledge economy, where production is focused on 'knowledge-based assets', such as software, research and development (R\&D) and human capital (Brinkley, Fauth, Mahdon \& Theodoropoulou, 2009). Knowledge work has largely been driven by the commercialisation of the internet in the early 1990s, as well as advances in information and communication technologies (ICTs). These developments have profoundly influenced the way we work: workplaces across industry are populated by computers, assorted work tasks would be impossible without the aid of technology and employees often communicate virtually, rather than in person. Indeed, the smartly-dressed commuter, talking loudly on a mobile phone whilst holding a takeaway coffee is perhaps one of the most recognisable stereotypes of the $21^{\text {st }}$ Century worker.

The trend towards virtual modes of working occurred in the 1990s, at the same time as researchers began to investigate workplace bullying as a construct of interest. Since then, different perspectives have been adopted to investigate various forms of bullying. It has been studied as a gendered phenomenon (Salin \& Hoel, 2013), as a means of discriminating against particular social groups (Fevre, Lewis, Robinson \& Jones, 2012; Fevre, Robinson, Lewis \& Jones, 2013) and as a multi-faced construct, involving empirically distinguishable forms of behaviour (Escartín, Rodríguez-Carballeira, Gómez-Benito, \& Zapf, 2010). However, until recently little research has addressed bullying behaviour channeled through technology, otherwise known as cyberbullying.

Public interest in cyberbullying has largely been stimulated by media publicity of several high-profile cases where online bullying has been linked to suicide among teenagers (Vandebosch, Simulioniene, Marczak, Vermeulen \& Bonetti, 2013). Yet, recently it has been recognised as an issue that affects a broader proportion of society. In 2016, technology firm Norton reported that $52 \%$ of 536 New Zealand women had been harassed online (Symantec, 2016). Another study surveyed 3,699 adults from the United States, finding that 
cyberbullying had most commonly been experienced in adulthood, rather than during elementary school, middle school, high school or college (Kowalski, Toth \& Morgan, 2017). In the workplace, research into cyberbullying represents an exciting new area of study given the ubiquity of computing technologies in working life and the flexibility offered by virtual work practices. It was recently estimated that 1.3 billion people would be working virtually by 2015 (Johns \& Gratton, 2013) and the use of virtual teams by multinational organisations continues to rise (Gilson, Maynard, Young, Vartiainen \& Hakonen, 2015). The potential benefits of computer-mediated technologies are vast, both from a productivity and an employee well-being perspective. However, a lack of guidance regarding proper use of communication technologies can undermine organisational efficiency and employee health. Rules regarding what employees can say on private social media sites vary between companies. In some organisations it is a sackable offense to post abusive, prejudiced or defamatory information online, even when it is posted outside of working hours. This presents a need for organisations to present clear guidance, so that employees understand how they are expected to communicate online, but also so they know when to switch off from work to safeguard their well-being.

Notably, trends towards virtual working have implications for future research on workplace bullying, as the primary means by which a significant proportion of employees communicate with their colleagues and other stakeholders will be via ICTs, rather than face-to-face (Farley, 2015). It has therefore been suggested that cyberbullying will become more prevalent in working life (D’Cruz \& Noronha, 2013). The aim of this chapter is to summarise the extant literature on workplace cyberbullying. First, we examine the criteria used to define workplace cyberbullying and discuss similarities and differences with traditional workplace bullying. Second, we discuss the behaviours involved and the actors that perpetrate, experience and witness them. Third, we present an overview on the empirical findings identified thus far, as well as the theoretical explanations for why people engage in cyberbullying. Fourth, we discuss some of the ways that targets and organisations can counter cyberbullying. Finally, we point out the relevance of the work context in the unfolding of workplace cyberbullying and outline suggestions for future research. In doing so, we hope to provide a comprehensive overview of research to date, combined with fruitful areas for future exploration. 


\title{
Understanding Workplace Cyberbullying
}

\author{
Cyberbullying in the Youth Context
}

Reviewing the key debates from the youth literature is important as research on traditional workplace bullying was galvanised by the pioneers who first investigated bullying in schools. The same is true of cyberbullying, which has primarily been studied among children and adolescents before being investigated within organisations (Kowalski, Giumetti, Schroeder \& Lattanner, 2014; Tokunaga, 2010). In the youth context, cyberbullying has been defined as “An aggressive, intentional act carried out by a group or individual, using electronic forms of contact, repeatedly and over time against a victim who cannot easily defend him or herself” (Smith et al, 2008, p. 376). Cyberbullying acts may be text-based (e.g. emails, text messages), visual (e.g. photos, videos) or verbal (e.g. voicemails, telephone calls) and they can occur through multiple mediums, including social media, mobile phones and email. The definition outlined by Smith et al (2008) stresses three main elements: (1) an intent to harm the target, (2) some repetitiveness and (3) an imbalance of power between the perpetrator(s) and the victim. These are the same criteria that have been applied to define traditional school bullying since the early 1980s (Olweus, 2013).

Using these criteria to conceptualise cyberbullying has been the subject of considerable debate, as several authors have questioned the applicability of power imbalance and repetition to the online context (Smith, del Barrio \& Tokunaga, 2013). A further criticism suggests that it is not practical to distinguish cyberbullying from a broader construct of cyberaggression, which involves all kinds of victimisation channeled through technology (Smith et al, 2013). Indeed, Kowalski et al (2014) presented an expansive review of cyberbullying definitions, many of which did not use repetition or power imbalance as definitional criteria, and are thus more aligned with cyberaggression. Nonetheless, authors who have examined the definitional issues in detail have presented a strong case that the same criteria can be used for both traditional bullying and cyberbullying (Olweus, 2013; Smith et al, 2013).

Another prominent debate in the youth context concerns whether cyberbullying is sufficiently different from traditional (otherwise known as offline or face-to-face) bullying to warrant tailored investigation. On one side of this debate, researchers claim there are important 
differences between these forms of bullying that influence perpetration motives and outcomes for targets (Slonje, Smith \& Frisén, 2013; Smith, 2012a). Others claim that cyberbullying is a relatively low-frequency phenomenon and that many similarities exist between traditional bullying and cyberbullying; thus, they may be valuably clustered together under the same conceptual umbrella (Olweus, 2012; Olweus 2013). Due to the relative infancy of this research area, more empirical work is needed to give weight to these arguments.

Organisational scholars can learn much from the youth literature as there are many similarities in the nature of bullying across children and adults (Nielsen, Tangen, Idsoe, Matthiesen \& Magerøy, 2015). However, the definition of workplace bullying has developed in a different manner to school bullying, as many authors believe it is not feasible to use the intent to harm criterion in the work context. Given the debate that started in the youth context, in the next section we will discuss whether the criteria used to define traditional workplace bullying (See D’Cruz this volume) can be applied to define workplace cyberbullying.

\section{Defining Workplace Cyberbullying}

Before discussing the criteria that should be used to operationalise workplace cyberbullying, it is useful to consider why a common definition is helpful to researchers and practitioners. From a research perspective, an agreed conceptual understanding facilitates the development of a consistent body of knowledge, as different researchers can investigate workplace cyberbullying with a common understanding of what it entails. The danger of not using a clear definition is that without systematically measuring definitional components, the prevalence of cyberbullying may be over-estimated or under-estimated (Tokunaga, 2010). Similarly, if different definitions are used to investigate cyberbullying, relationships with other variables will vary across studies, which will inhibit clarity on the size of such relationships. From a practitioner perspective, a consistent definition is needed so that human resources (HR) professionals, occupational health and safety (OHS) personnel, therapists, lawyers, regulatory authorities, policy makers, unionists and other interventionists can identify and address cyberbullying. Research suggests that practitioners are struggling to tackle cyberbullying because it is not well defined (West, Foster, Levin, Edmison \& Robibero, 2014). A commonly understood definition is therefore needed to facilitate policydevelopment and training, as well as to enable the identification of cyberbullying when it 
occurs. Drawing on the traditional workplace bullying literature, the following section will discuss whether the criteria relied on here, namely, repetition and persistence, power imbalance and intent to harm, can be used to define cyberbullying.

\section{Repetition and Persistence}

Different forms of workplace aggression have been investigated over the last 20 years including abusive supervision, incivility and social undermining. Researchers contend that the main criteria that differentiates bullying from other constructs is the repetition and persistence of the behaviour, whereby the target is exposed to systematic negative acts over time (Nielsen, Hoel, Zapf \& Einarsen, 2015).

A number of researchers have indicated that repetition is an important indicator of workplace cyberbullying (Coyne et al, 2016; Farley, Coyne, Axtell \& Sprigg, 2016; Forssell, 2016; Zhang \& Leidner, 2014). However, our conceptualisation of repetition will need to expand beyond the rigid notion espoused within traditional bullying. While cyberbullying may include a perpetrator embarking on a campaign of abuse directed at a specific target over time, it will also involve negative behaviors in the public domain which, though perhaps enacted just once, are continually present, viewed by a large audience, repeated by bystanders and/or re-posted by others (D’Cruz \& Noronha, 2013). The repetition and persistence in this context results in a victim experiencing on-going trauma because of the continuation and spread of the act (Dooley, Pyżalski \& Cross, 2009) even when the original protagonist is no longer directly involved.

In the cyber context, debate on what constitutes repetition has been influenced by the distinction between private and public communication. Private communication involves oneto-one correspondence, although team, departmental and organisational communication can also be considered private (to a lesser extent), as it occurs within the confines of an organisation. Comparatively, public communication comprises information and messages that are accessible by members of the public, such as messages posted on publicly accessible blogs, forums and social media websites.

Some authors argue repetition is a necessary indicator of cyberbullying in private contexts, but not in public contexts, where communications are distributed to a much larger audience (Langos, 2012). Others suggest that not all publicly distributed single behaviours can be considered cyberbullying (Vranjes, Baillien, Vandebosch, Erreygers \& De Witte, 2017). 
Instead Vranjes et al (2017) argue that only one-off acts which directly intrude into a target's private life should be classified as cyberbullying (e.g. having private information hacked, having private videos shared online). This is because the target may experience repeated and persistent fear that their information will be released publicly.

In our view, the extent to which cyberbullying occurs in public/private settings and whether it intrudes into a target's private life are not factors that should inform the way cyberbullying is defined. Both factors may influence the relationship between experiencing cyberbullying and outcomes for targets, potentially acting as moderators in this process. Rather, the central issue that should inform the definition of workplace cyberbullying is not where and how it occurs, but the extent to which it results in an enduring, ongoing situation. In online scenarios, targets can even act to foster repetition by revisiting online behaviour directed at themselves, such that they become quasi-perpetrators (D’Cruz \& Noronha, 2017a, forthcoming). Accordingly, we consider repetition in all its forms (e.g. the continuity of abuse posted online, acts repeated by bystanders) as the central criterion that should be used as a definitional indicator. Therefore, from our perspective, the criterion of repetition adopted to define traditional bullying can be adopted for cyberbullying, but this narrow view of repetition needs to be expanded to account for the multiple ways repetition can occur online.

\section{Power Imbalance}

Power is conceptualised as the ability of a person to impose their will on another through the control of resources (Anderson \& Galinsky, 2006) or a psychological property that people perceive they possess/lack in relations with others (Hershcovis, Ogunfowora, Reich \& Christie, 2017). Workplace bullying has primarily been studied as an interpersonal situation, involving interactions between a perpetrator (or set of perpetrators) and a victim. In this situation, the target perceives himself/herself as lacking power in relation to the perpetrator(s). There are a number of reasons why traditional bullying victims may perceive themselves as powerless, including differences in expertise, physique, number of allies, access to resources and organisational status. Yet, while targets of bullying often feel powerless in their situation, it has been demonstrated that they simultaneously take steps to resist it, which can provide a sense of autonomy (Lutgen-Sandvik, 2006; Noronha \& D'Cruz, 2013). For example, resistance strategies include direct confrontation, withdrawing labour and voicing concerns about the situation to others. This has led to a view that power within bullying situations should not be seen as being weighted heavily in favour of the perpetrator, 
but rather as an entity that can be drawn upon by both parties through differing means (D’Cruz, 2016).

This perspective may inform how we think about the different sources of power available to perpetrators and victims in cyberbullying situations, although akin to the debate on repetition our understanding of power may need to be revisited for online bullying. Cyberbullying often transpires when the perpetrator and target are in separate locations, which means that displaying power through physical intimidation is a less effective option for cyberbullying perpetrators. Nonetheless, computer-mediated communication (CMC) offers perpetrators different ways of asserting control over targets. Notably, technology allows targets to be contacted through a variety of channels, as it is not uncommon for an employee to have a work phone number, email address and social media account. These "electronic leashes" can tie employees to their workplaces and provide perpetrators with greater access to targets outside of working hours. This is especially the case when employees are implicitly required to stay in touch with work at all times by checking their work emails. As such, perpetrators can exert control by sending communications at any time, leaving targets feeling trapped (D’Cruz \& Noronha, 2013).

Similarly, communication between colleagues is no longer restricted to work-related media, as many employees choose to communicate outside working hours on personal media and devices (Mainiero \& Jones, 2013). This can cause headaches for HR professionals as their professional and legal obligations when these communications turn sour is often unclear. Indeed, perpetrators may take advantage when organisations do not have explicit guidance on social media and harassment, especially if they believe that there are no constraints on how they communicate outside of work. Therefore, a power imbalance may arise when perpetrators believe there is no policing agent to punish their behaviour and when targets believe there is no recourse to online harassment experienced outside working hours. Perpetrators can also hold power by attempting to remain anonymous. Research on cyberbullied students found that those unaware of the perpetrator's identity experienced feelings of powerlessness and frustration (Vandebosch \& Van Cleemput, 2008). This may be because anonymity makes it difficult to confront the perpetrator, put their actions into perspective or report them to a relevant authority (D’Cruz \& Noronha, 2017b). In all likelihood, it will be challenging for a perpetrator to send continuous abusive messages anonymously to a victim within a work context. This is particularly the case when the perpetrator and victim work in the same organisation, as email addresses and caller identities 
(IDs) usually display peoples’ identities, while internet protocol (IP) addresses can reveal the sender's location. However, social media websites are often used by professionals to publicise their work, potentially increasing harassment from anonymous individuals. Overall, while anonymity is mooted to play a role in the power dynamics of cyberbullying, the extent that anonymous cyberbullying occurs in the working context needs further investigation.

Although some aspects of technology allow perpetrators to exert control over targets, there is some evidence that targets can draw upon technological features to resolve their situation. For instance, communication through technology is evidenced by a 'digital footprint' which is a permanent record of specific events (e.g. telephone call logs, emails and text messages). Research in the Indian information technology (IT) sector reveals that targets have used footprint evidence to stop cyberbullying (D’Cruz \& Noronha, 2013). It is therefore important to note that although technology offers perpetrators new ways of asserting power and control, technological features can also enable targets to resolve their situation.

The extant research suggests that power remains an important criterion that can be used to define workplace cyberbullying. Yet, like repetition, the way that power is displayed changes in the online context, as perpetrators and victims can use features of computer-mediated communication (e.g. greater access, anonymity and the digital footprint) to tip the balance of power in their favour (D’Cruz, 2016).

\section{Intent to Harm}

Marking a departure from the youth context (Dehue, Bolman \& Vollink, 2008; Huang \& Chou, 2010; Smith et al., 2008), intent to harm does not currently appear in many workplace cyberbullying definitions (D’Cruz \& Noronha, 2017b; Farley et al, 2016; Forssell, 2016; Vranjes et al, 2017). ICTs do not transmit all the communication cues that can reveal the real meaning of a message, such as voice tone and body language, resulting in difficulty establishing intent when bullying commences online (Farley et al, 2016). Additionally, individuals find it difficult to express and perceive emotion in workplace emails (Byron \& Baldridge, 2005) and a lack of understanding on a communication partner's work context and constraints can also make messages difficult to interpret (Clark \& Brennan, 1991). The issue is further compounded by the possibility that the digital footprint left by online communications may lead perpetrators to enact bullying behaviours that are more subtle than offline bullying behaviours. 
Interestingly, in the youth context it has been suggested that the views of a 'reasonable outsider' can be used to judge the degree of intent involved in bullying and cyberbullying situations (Smith et al, 2013). However, who determines the judgement of intent as a 'reasonable outsider' in the context of work has not been fully articulated, especially as targets are often skeptical about the impartiality of HR professionals when handling bullying complaints (Chekwa \& Thomas, 2013; D’Cruz \& Noronha, 2010) even when a digital footprint has been left (D’Cruz \& Noronha, 2017b). Accordingly, it seems appropriate that cyberbullying definitions exclude intent as a central criterion.

\section{Summary}

A clear, concise workplace cyberbullying definition is needed to help researchers and practitioners investigate and address the phenomenon. Early attempts at defining workplace cyberbullying have been heavily influenced by traditional bullying definitions, which stress repetition and power imbalance as central elements (Farley et al, 2016; Forssell, 2016; Zhang \& Leidner, 2014). Given the arguments outlined in this section, we believe that repetition and power imbalance are appropriate definitional indicators of cyberbullying, albeit these criteria take on different forms online. We therefore subscribe to the view that workplace cyberbullying can be defined as " a situation where over time, an individual is repeatedly subjected to perceived negative acts conducted through technology (e.g. phone, email, web sites, social media) which are related to their work context. In this situation the target of workplace cyberbullying has difficulty defending him or herself against these actions" (Farley et al, 2016, p. 299). This definition suggests that cyberbullying and traditional bullying can be conceptualised using the same overarching framework. Therefore, cyberbullying is not conceptually different, but refers to the same phenomenon enacted online. Critics of this approach may question why a cyberbullying construct is needed, as cyberbullying could be clustered with traditional bullying under the same conceptual umbrella. However, a significant reason for investigating cyberbullying separately is that it has certain unique characteristics that may affect how it occurs. The next section will review these characteristics.

\section{Features of Workplace Cyberbullying}

Research from the school context has identified several features that differentiate 
cyberbullying from traditional bullying (Smith, 2012b). A number of these features are also relevant to the context of work; these are as follows:

1. Cyberbullying is primarily an indirect form of bullying, as it takes place online rather than face-to-face. Indirect aggression involves acts that are directed at a target, but not in a face-to-face manner (Björkqvist, Lagerspetz \& Kaukiainen, 1992). Enacting this form of aggression can allow perpetrators to remain anonymous.

2. The perpetrator and target are usually in separate physical locations when an act occurs. This means that the person sending the message cannot see the receiver's reaction to it, nor can the receiver see the sender.

3. Many cyberbullying acts remain accessible and visible for long periods of time. For example, text-based, picture and video messages leave a digital footprint, which enables those who have received messages to continuously review them, long after the original send date.

4. Cyberbullying can be experienced anytime and anywhere as technology enables people to send and receive messages whenever they have a device in hand.

5. Cyberbullying can potentially be viewed by a much larger audience than traditional bullying.

6. There is a more complex array of bystander roles in cyberbullying situations: the bystander can view the message online, or they may be physically present with either (a) the perpetrator or (b) the target when a message is sent or received.

These features have been highlighted in the workplace cyberbullying literature (Forssell, 2016) and qualitative studies have illustrated how they affect people (D’Cruz \& Noronha, 2013; Heatherington \& Coyne, 2014). Studying these features can uncover knowledge on the ways that traditional bullying and cyberbullying differ. For example, researchers have argued that they may produce different motivations for perpetrators and different consequences for targets (Menesini, Nocentini \& Camodeca, 2013). In Table 1, three real workplace cyberbullying cases are described to highlight how these features affect cyberbullying situations. 
These cases illustrate how the features of cyberbullying can potentially make it quite a different experience to traditional workplace bullying. For example, in Case 1, the perpetrator was able to maintain anonymity for an extended period and the target was not even aware of the messages until she was informed by her fiancé. This indicates that cyberbullying can occur without the target being aware of it. This can also happen with traditional workplace bullying, for example a target might discover that he/she has been the subject of office gossip. Nonetheless, this situation was quite different from a traditional bullying case, as the target's fiancé was the one receiving the messages, which shows that cyberbullying can go beyond the confines of a workplace and potentially affect personal relationships.

Like Case 1, a physical separation between the perpetrator and the target was also a factor in Case 2, as the target felt that she was being subjected to cyberbullying in her own home. Therefore, unlike face-to-face bullying (which often occurs when the perpetrator is in the immediate vicinity), cyberbullying can exert an impact outside of the physical workplace. Moreover, as opposed to the premeditated acts described in Case 1, the target describes messages from her manager as 'cold'. This suggests that the manager might not have been aware that the messages were being interpreted in such a negative manner, as he/she was not able to see the target's reaction to them.

In Case 3, the physical location was again a factor as the target discovered that she had been 'unfriended' whilst outside of the workplace. Interestingly, the Fair Work Commission ruled that this was unreasonable behaviour, despite the fact that it was enacted on a personal social media site. This suggests that even acts that occur outside working hours on non-work platforms could be considered workplace bullying. The case is also interesting as it describes a specific act 'unfriending' that is unique to social media.

\section{Summary}

Research on the unique features of workplace cyberbullying is still fairly limited. However, it has been suggested that depending on the context of a case, certain features could either make matters worse, or help with resolution. For example, large audiences could make a cyberbullying situation worse if the target experiences public humiliation. Yet, a public audience could help to resolve the situation if bystanders speak out against cyberbullying. It 
therefore seems that although certain unique features have the potential to make matters worse for targets, there are also situations where features of cyber communication play out in their favour.

\section{Workplace Cyberbullying Behaviours}

In addition to cyberbullying's 'unique features', research has focused on the behaviours that encompass the construct and particularly whether it involves new and unique behaviours compared with traditional bullying (Kowalski et al, 2014). Empirical investigation reveals cyberbullying involves many of the same behaviours (e.g. threats, teasing, name calling; Farley, 2015). By contrast, research also illustrates that it involves novel behaviours, such as spreading computer viruses (Forssell, 2016).

Olweus (2012) argues that one way to identify whether cyber behaviours really are different is to examine the overlap between similar forms of traditional bullying and cyberbullying. This can be done by investigating whether the overlap between a particular form of online and offline bullying (e.g. exclusion) is greater than the overlap between different forms of traditional bullying (e.g. physical aggression and exclusion), thereby providing an answer as to whether it is the behaviour or the medium which is more differentiated.

In the work context, interviews with Canadian HR professionals revealed the behaviour most commonly encountered by respondents was employees posting inappropriate content about their coworkers online, particularly on social media (West et al, 2014). Additional behaviours discussed included spreading jokes over email and cyber stalking after the collapse of an office romance. Interestingly, several interviewees commented that certain cyberbullying behaviours had not been encountered by HR and that a consensus on what was acceptable cyber behaviour had not yet been established.

Parallel to traditional bullying research, behavioural-based measures have been adopted to determine the extent of cyberbullying behaviours. In a Swedish sample, Forssell (2016) found that more commonly experienced behaviours included: not receiving responses to emails/texts sent to supervisors, having necessary work-related information withheld, having a virus intentionally sent to one's email address and receiving aggressively worded message. In a UK (United Kingdom) sample, commonly experienced behaviours involved being sent 
conflicting information, being bypassed in group communications relevant to your work role and receiving messages that have a disrespectful tone (Farley, 2015). During one study, factor analyses revealed that two different forms of cyberbullying could be interpreted: work-related cyberbullying (behaviour associated with the target's work) and person-related cyberbullying (behaviour related to the target's character; Farley, 2015). These two forms of cyberbullying reflect a distinction identified during research on traditional bullying (Einarsen, Hoel \& Notelaers, 2009). The same distinction was identified during another study that examined how traditional workplace bullying and cyberbullying affected target's job satisfaction and mental strain (Coyne et al, 2016). Interestingly, work-related cyberbullying correlated to a greater extent with work-related traditional bullying $(\mathrm{r}=.82)$, than it did with person-related cyberbullying $(\mathrm{r}=.60)$. The same was true of person-related cyberbullying which was more positively correlated with person-related traditional bullying $(r=.73)$, than it was with the work-related cyberbullying factor $(r=.60)$.

\section{Summary}

Debate will continue as to whether cyberbullying behaviours are simply traditional bullying acts being conducted through a new medium, or whether they represent something more unique. Given the evidence presented thus far (Coyne et al, 2016), we contend that the behaviours are the same, regardless of whether they occur online or offline. In this respect, it seems that bullying behaviours are more differentiated by their nature, than by whether they occur online or offline. Future research could be conducted using the procedures suggested by Olweus (2012) to determine whether specific forms of cyberbullying share more variance with other forms of cyberbullying, or with their offline counterparts. From a practical perspective, it's important to identify and provide practitioners with details on what constitutes cyberbullying so that this information can be used to create policies and guidance on unacceptable behaviour (Farley, 2015).

\section{Perpetrators, Victims and Bystanders}

Recently the question has been raised as to whether labels such as 'perpetrator' and 'target' are practically or theoretically meaningful (Hershcovis \& Reich, 2013). It is possible that 
labels such as 'perpetrators', 'targets' and 'bystanders' have been adopted as a means of describing actors in the process, rather than as labels than hold practical value. It could be argued that the process should be described without referring to value-laden terms, especially when bullying is caused by work environment (Salin 2003) or organizational design (D’Cruz, 2015) factors in which workplace-linked features cause people to engage in bullying behaviour. In such scenarios, bullying may be initiated unconsciously, in response to a stimulus, as a result of poor job design or due to a culture of aggression. In which case, arguably the organisation should be held accountable for bullying behaviour rather than the individual. Nonetheless, there are cases where a clear 'bully' and 'victim' can be identified, for example, predatory bullying is said to occur when the perpetrator has an unprovoked intent to harm the target (Einarsen et al, 2011). In such instances, the terms 'perpetrator' and 'victim' seem warranted. Yet, when bullying occurs after a conflict has escalated, both parties may legitimately claim to have experienced bullying behaviours at different times (Hershcovis \& Reich, 2013). In these instances, the terms paint a misleading picture of the situation. Therefore, although we use the labels in this chapter, it should be noted that there are times when they are more or less appropriate.

\section{Perpetrators}

Traditionally, bullying was viewed as a phenomenon that occurred within the confines of an organisation. Einarsen (2000) defined it as instances where an employee is repeatedly subjected to negative acts from coworkers, supervisors or subordinates, a definition which seems to exclude organisational outsiders (Hershcovis, 2011). Though outsiders (e.g. customers, shareholders, members of the public) have the capability to abuse employees (D’Cruz \& Noronha, 2014; Korczynski \& Evans, 2013), their status as bullying perpetrators has rarely been considered. This is possibly because many outsiders have only fleeting contact with employees and therefore cannot enact persistent negative acts against them. As we have already detailed, computer-mediated communication changes this dynamic. CMC can facilitate repeated access to employees through organisational email, telephone and social media accounts and therefore, the potential for outsiders to enact bullying and ongoing harassment against employees is enhanced by CMC.

D'Cruz and Noronha (2014) used the term 'customer cyberbullying' to refer to aggressive behaviours enacted by customers towards front-line employees via computer-mediated 
communication. Research revealed that employees working in Indian call centres had been subjected to threats and rude remarks during calls, such as "Why should I trust a terrorist country” (D’Cruz \& Noronha, 2014; p. 186) and “You are a liar, why should I trust you” (p. 186). Other behaviours included sarcastic or bitter comments, shouting, swearing and intimidation. Some might question the extent to which this behaviour constitutes bullying under the traditional criteria, given it comes from an organisational outsider and is fairly short-lived. However, as discussed, the criteria of power imbalance and repetition changes in the online context. Therefore, one can see how employees might feel cyberbullied, given that power in these interactions generally lies with the customer, and call handers may receive several abusive calls in the same week. Further, calls are archived and can be replayed for performance evaluation and improvement purposes such that it is not only targets who are subjected to the abuse again, but their superiors also witness it (D’Cruz \& Noronha, 2015). There are certain industrial sectors that require employees to develop long-term relationships with organisational outsiders. In these situations, the potential for cyberbullying may be greater as the primary means of contact is likely to be via ICTs. For example, social workers have regular contact with their clients through text messages and phone calls. Additionally, sales people will manage client accounts for extended periods, in situations where the client may hold most of the power. Another profession involving an unconventional relationship between employees and non-employees is education. A study conducted in a Canadian university found that respondents had experienced cyberbullying to a greater extent from students than from their colleagues (Cassidy, Faucher \& Jackson, 2014). This suggests that cyberbullying may be more commonly enacted by those who are unconstrained by the sanctions that employees face for abusing colleagues. Organisations do attempt to control the behaviour of outsiders using various strategies, such as posters stating that abuse towards staff will not be tolerated, alongside warnings that harassment will be prosecuted (Wood, Braeken \& Niven, 2012). However, arguably, these sorts of warnings may be more difficult to enact online, where varying degrees of anonymity and a sense of freedom from being held accountable have been touted as reasons for why trolling (i.e. posting inflammatory messages online) occurs (Hardaker, 2010).

Another consideration is whether there are any demographic risk factors that increase one's chances of becoming a perpetrator. Due to anonymity and the separation of perpetrator and target, cyberbullying can be an indirect form of bullying. It has been suggested that men tend to enact direct forms of aggression, whereas women tend to enact indirect aggression to a 
greater extent (Zapf, Escartín, Einarsen, Hoel \& Vartia, 2011). There is scant evidence on the gender of cyberbullying perpetrators in the working context and evidence from the youth context is inconsistent (Kowalski \& Limber, 2007; Wang, Iannotti \& Nansel, 2009; Williams \& Guerra, 2007) which suggests a need for further research. Organisational status may also affect the extent to which people engage in cyberbullying. Baruch (2005) found that email bullying was conducted slightly more by managers than peers in a large multi-national organisation. However, junior doctors reported experiencing cyberbullying to a greater extent from their peers (who were reported as the main perpetrator in $35.6 \%$ of cases) than from individuals in other professional roles, such as consultants (the main perpetrators in $26 \%$ of cases) and managers (the main perpetrators in 19.2\% of cases; Farley et al, 2015). This runs counter to findings on traditional workplace bullying which often finds that managers or supervisors are the main culprits (Hoel, 2013). The inconsistency between these two studies suggests that the finding may be sector dependent.

\section{Victims}

Mirroring the early research on traditional workplace bullying (Leymann \& Gustafsson, 1996; Zapf, Knorz \& Kulla, 1996), to date studies on workplace cyberbullying have tended to examine the target's perspective. In terms of demographic risk factors for victim status, contrary to traditional bullying investigations, Swedish supervisors (Forssell, 2016) and New Zealand managers (Gardner et al., 2016) experienced more cyberbullying behaviours than non-supervisors and non-managers respectively. Qualitative research has also identified that managers are targeted by cyberbullying (D’Cruz \& Noronha, 2013). Dissatisfied employees may take to the internet to vent frustration with their manager's leadership style and overworked managers may face a daily barrage of emails from subordinates, which leaves them feeling harassed.

Regarding the gender of victims, Forssell (2016) found that men had experienced significantly more cyberbullying behaviours than women in a representative sample of Swedish adults, although there was no difference in the extent to which men and women selflabelled as cyberbullying victims. Comparatively, Cassidy et al. (2014) reported Canadian female faculty members had experienced cyberbullying to a greater extent than males.

The extent to which targets experience cyberbullying alongside traditional bullying has received some research attention. Mitchell et al. (2016) develop a taxonomy of bullying 
experiences within children and youth samples:

1. Only in-person involvement (i.e. no technology elements);

2. Mixed (both in-person and technology elements);

3. Only technology involvement (i.e. no in-person elements).

Within a work context, Privitera and Campbell (2009) found $10.7 \%$ of their Australian sample fell into the mixed category, whereas $23.3 \%$ could be classified as only in-person involvement. Comparatively, Coyne et al (2016) found that out of eighteen respondents (13.6\% of the sample) who could be classified as cyberbullying victims, fourteen (10.6\%) were also victimised offline. Both studies found that the prevalence of traditional bullying was higher that the prevalence of cyberbullying. However, a recent study found that North American adults experienced cyberbullying more commonly than traditional bullying (Kowalski et al, 2017), although this study looked at behaviours experienced in all the domains of their lives, rather than just work-specific acts.

\section{Bystanders}

The emergence of workplace cyberbullying as an area of interest has coincided at a time when more research is being conducted on bystander responses to workplace aggression (Reich \& Hershcovis, 2015). Bystanders are seen as an important group because they may represent one of the most effective ways of intervening against workplace aggression. Bystanders who step in to prevent bullying and check on the well-being of targets may drastically reduce its negative impact. Indeed, bystanders represent such an important group that the KiVa bullying programme aimed at youth and children promotes bystanders as a central element of the intervention. Unlike other interventions, KiVa aims to enhance selfefficacy and anti-bullying attitudes among bystanders through highlighting bullying issues, promoting empathy, and including discussions with witnesses on what can be done to support the target in the future.

Paull et al., (2012) posit that our understanding of the role of bystanders in traditional workplace bullying is currently limited, with only a few researchers considering this group (Bauman \& Del Rio, 2006; D’Cruz \& Noronha, 2011; Mulder et al, 2015). Within cyberbullying, the "variety of bystander roles...is more complex than in most traditional bullying. There can be three main bystander roles rather than one: the bystander is with the perpetrator when an act is sent or posted; the bystander is with the victim when it is received; 
or the bystander is with neither, but receives the message or visits the relevant Internet site.” (Li et al., 2012, p.8). Yet, D’Cruz and Noronha (2013) caution that contingent on how workplace cyberbullying is enacted, there may be no bystanders at all. This occurs when communication is shared exclusively between perpetrator and target, with neither party involving others. Even so, when there are bystanders, the online environment results in “...less opportunity for bystander intervention” (Slonje \& Smith 2008, p.148). Presently, we know very little about bystander behaviour within workplace cyberbullying. However, Coyne et al (2017), using a quasi-experimental design across two different employee samples, illustrated that bystanders were least likely to support the victim and more likely to agree with perpetrator actions for online/work-related negative acts. Evidently, more systematic research on bystander behaviour online is needed to allow researchers and practitioners to fully understand this group.

As well as being a group that can prevent workplace bullying, it has been argued that bystanders can experience ill-health by witnessing it (Sims \& Sun, 2013). The issue was addressed by Coyne et al (2016) who examined the relationship between witnessing cyberbullying and well-being among a sample of university employees. The study found that there was no relationship between witnessing cyberbullying and well-being, a finding which was explained by the deindividuation effect of virtual working. This effect makes people less sensitive to the feelings of others when working online, therefore the reduced social cues that are available when people communicate online may reduce empathy (Ang \& Goh, 2010). Although this may shield bystanders from the negative impact of witnessing bullying, it potentially leaves the victim more isolated as they may not receive the same level of social support that they would if they were targeted offline.

\section{Summary}

The findings on perpetrators, victims and bystanders of cyberbullying are frustratingly mixed. Where one study (Forssell, 2016) finds evidence for a particular trait or characteristic associated with perpetrators or victims, there is usually another study which has found contrary evidence (Cassidy et al, 2014). This illustrates the need for studies which use representative samples, such as the one conducted by Forssell (2016). This contradictory evidence also suggests that there is likely to be large variation across countries, sectors and professional roles, particularly with respect to the extent that someone has to engage with 
technology as part of their job. As research continues, it will be important to identify groups who are at greater risk of experiencing and witnessing cyberbullying, so that interventions can be targeted.

\section{Empirical Findings}

\section{Prevalence}

There have been few studies with an explicit focus on workplace cyberbullying, and fewer still that have examined prevalence. Nevertheless, many studies that have measured cyberbullying prevalence have also measured traditional bullying, which allows for a comparison. Two main methods of measuring bullying are generally adopted in workplace bullying research: the self-labelling approach and the behavioural experience method (Nielsen, Matthiesen \& Einarsen, 2010). Self-labelled victimisation is estimated by way of a single-item (usually preceded by a definition) which asks whether the respondent has been a victim of bullying in the past 6-12 months. Comparatively, the behavioural experience method involves asking respondents how often they have been subjected to an inventory of bullying behaviours. Table 2 shows a collection of published workplace cyberbullying studies which assessed prevalence. Most studies which measured traditional bullying alongside cyberbullying found that the former was more prevalent, when directly comparing the measurement method. Forssell (2016) used a nationally representative sample in Sweden and found that just $0.7 \%$ of respondents labelled themselves as cyberbullying victims, whereas 3.5\% self-labelled as traditional bullying victims.

Insert Table 2 Here

Due to a lack of longitudinal data, it is impossible to definitively answer the question of whether cyberbullying is increasing within a working context. However, it is clear that the prevalence of ICTs in organisations is increasing. Data from Eurostat indicates the percentage of organisations in European Union (EU) countries with a fixed broadband connection increased from 86\% in 2011 to 90\% in 2013 (Eurostat, 2014). Similarly, the percentage of 
organisations within EU countries that used social media (e.g. Facebook, LinkedIn, YouTube) increased from 28\% in 2013 to 36\% in 2015 (Eurostat, 2016). Although these data do not directly imply workplace cyberbullying is on the rise, they do suggest that more employees have access to ICTs than ever before. It may be the case, as has been argued in the youth context (Smith, 2012a), that the prevalence of workplace cyberbullying rose between the late 1990’s and 2005 when internet and mobile phone technology became commonplace, followed by a levelling off from 2005 onwards.

\section{Impact}

Researchers have sought to address the impact of workplace cyberbullying and whether it is more severe than traditional bullying. Workplace cyberbullying has been shown to be related to several negative outcomes including anxiety (Baruch, 2005), frustration (Hong et al., 2014) and stress (Snyman, \& Loh, 2015). These results should be interpreted with some caution as they have used cross-sectional designs with the limitation that it is not possible determine causal relationships between cyberbullying and hypothesized outcome variables. Indeed, Gardner et al. (2016) found poor health was associated with cyberbullying three months later. Therefore, future research on the topic should seek to assess cyberbullying and health variables across several time points to determine the direction of these relationships. Nonetheless, extrapolating from research on the consequences of traditional workplace bullying (See Volume 2, Section A for relevant chapters), it would be surprising if cyberbullying did not result in detrimental outcomes for the target.

Given the dearth of research into workplace cyberbullying, it is too early to say whether its impact is lesser or greater than traditional workplace bullying. It has been argued that the unique characteristics of cyberbullying can make the experience more stressful for victims (Coyne et al, 2016; D’Cruz \& Noronha, 2013; Dooley et al, 2009). For instance, it can invade the walls of a home which has normally been considered a safe environment. Ford (2013) examined some of these characteristics directly, investigating whether location and anonymity moderated the relationship between virtual harassment and fear of future harassment. Anonymity amplified the association between virtual harassment and fear of future harassment, such that greater perpetrator anonymity was related to higher levels of fear in the targets. Indeed, not knowing the identity of the perpetrator exacerbates target distress, 
leaving them perennially puzzled about who or what has triggered the bullying and indecisive about the most suitable course of action (D’Cruz, 2016).

One of the few studies which has addressed the issue of the impact of workplace cyberbullying vis-à-vis traditional bullying, found that cyberbullying correlated significantly more strongly with job dissatisfaction than traditional workplace bullying (Coyne et al, 2016). However, research from the youth context suggests that the impact of cyberbullying is more likely to depend on the nature of the behaviour rather than the medium used to perpetrate the act. For instance, one study asked participants to rate how upset they would be if they were subjected to eight face-to-face bullying behaviours compared with eight equivalent cyberbullying behaviours (Bauman \& Newman, 2013). The researchers found that the more severe acts were rated as more harmful, regardless of whether or not they occurred online or offline.

\section{Summary}

Research findings indicate that cyberbullying is less prevalent than traditional workplace bullying. This trend may or may not change as time goes on, as computer-mediated communication will likely increase, but people may be wary about enacting explicit forms of bullying online, which may lead to an increase in subtle forms of cyberbullying. Research on the impact of cyberbullying is developing; however, advanced research designs are needed to identify causal relationships and tease apart the influence of cyberbullying relative to traditional bullying.

\section{Explanations for Workplace Cyberbullying}

The research on traditional workplace bullying has proffered two hypotheses for why individuals enact bullying. The work environment hypothesis suggests that people bully due to factors in the work environment, such as poor work design and laissez faire leaders. The person-centered hypothesis suggests that individual characteristics make people more likely to become perpetrators or targets. Given the similarities between traditional bullying and cyberbullying, many of the findings on the antecedents of traditional bullying (See Volume 2, Section A for relevant chapters) should be applicable to cyberbullying. For example, strong 
associations have been identified between leadership behaviour, role conflict, role ambiguity and social climate, and traditional workplace bullying (Skogstad, Torsheim, Einarsen \& Hauge, 2011). Similar findings were reported in relation to cyberbullying, which was negatively correlated with perceived organisational support and the perceived effectiveness of an organisation's bullying strategy (Gardner et al, 2016). However, there may be reasons why people engage in cyberbullying that are independent from motivations for engaging in traditional bullying.

The literature has not developed to a stage where motives for engaging in workplace cyberbullying are well-known. However, a meta-analysis of the youth literature identified that enacting cyberbullying was moderately correlated with being a perpetrator of traditional bullying, normative beliefs about aggression and moral disengagement (Kowalski et al, 2014). Regarding personality, it was recently found that agreeableness and sadism were personality predictors of engaging in both traditional bullying and cyberbullying among 1621-year old’s (van Geel, Goemans, Toprak \& Vedder, 2017). Qualitative research perhaps offers more rounded reasons why people consider engaging in cyberbullying. Interviews with students suggest motives for perpetrating cyberbullying could be internal or external (Varjas et al, 2010). Internal motives included revenge, boredom, getting a reaction and showing others that you are tough. External motives included wanting to avoid face-to-face confrontation and a perceived lack of consequences for conducting it.

In the workplace, a few theoretical models have been proposed to explain cyberbullying, which have been summarised by Coyne and Farley (in review). Two workplace bullying specific theories focus on a cognitive or an emotional explanatory process. Zhang and Leidner (2014) used the rationale choice theory of corporate crime to explain why employees may engage in cyberbullying. This argues that individuals weigh up the costs associated with (1) formal sanctions, informal sanctions and shame, and (2) moral inhibitions before deciding whether to act. These factors alone however, cannot explain why individuals choose to engage in a behaviour which they know may be sanctioned and morally wrong. Instead, perpetrators use other strategies to justify their behaviour, including denying responsibility for their actions, denying that harm has been caused, denying there is a victim and suggesting that the behaviour has been enacted for a greater good (e.g. productivity). This model can be contrasted with the emotion reaction model of workplace cyberbullying (Vranjes et al, 2017). The authors hypothesize stressors in the work environment (e.g. organisational change, team conflict) lead to anger which in turn motivates a person to engage in cyberbullying. The 
model suggests that control appraisal moderates the relationship between stressors and emotions, such that anger arises when the stressor is perceived to be under another person's control. In addition, attempting to suppress the anger is hypothesized to exacerbate cyberbullying perpetration.

\section{Summary}

The reasons why people engage in workplace bullying have been investigated at length and multiple reasons have been proposed. What we do not know at this point is whether there are novel reasons why an individual may be inclined to engage in cyberbullying, but not traditional bullying. In the workplace, enacting cyberbullying seems to come with greater risk, as many cyber behaviours leave a digital footprint, however this does not seem to have deterred perpetrators. It may be the case as Zhang and Leidner (2014) argue that the benefits outweigh the costs.

\section{Intervening Against Workplace Cyberbullying}

The main question regarding interventions is whether novel strategies are needed for cyberbullying which exist independently from traditional bullying prevention efforts. There is very little research on the efficacy of traditional workplace bullying interventions, which means that there is no way of telling whether these could also work for cyberbullying. In the youth context, there is some evidence to suggest that interventions against traditional bullying work to reduce cyberbullying (Gradinger, Yanagida, Strohmeier, \& Spiel, 2016; Williford et al, 2013). In this chapter, we argue that cyberbullying and traditional bullying are conceptually identical, accordingly we would advise an integrated approach to prevention and resolution. This seems preferable for practitioners, as an overarching approach that covers all forms of bullying behaviours should be less time-consuming and involve greater clarity than developing new interventions for different types of bullying. However, any integrated approach should mention cyberbullying explicitly, as it will be important for practitioners to be aware of the unique characteristics of cyberbullying. The fact that cyberbullying can occur outside working hours and be perpetrated by organisational outsiders complicates the way that organisations can respond, and practitioners should implement processes to address these 
risks.

The unique characteristics may additionally have a function in helping targets to resolve their situation. Cyberbullying leaves a trail of evidence which has been used by victims to resolve their situations (D’Cruz \& Noronha, 2013). Additionally, one method available to certain cyberbullying targets is to control when and how they respond to cyberbullying behaviours. Control is a well-known job resource that serves to reduce the impact of stressors by enabling employees to deal with demands when they best able to do so (Karasek \& Theorell, 1990). Since perpetrators and targets are often separated when cyberbullying occurs, targets may be able to screen calls from the perpetrator's number and call back when they feel best prepared to do so. Similarly, communications received via email, discussion boards or social media are asynchronous in that messages can be read and responded to as schedules permit. Therefore, a target can write back after they have had the opportunity to collect their thoughts and prepare an appropriate reply. Finally, a conflict model of computer-mediated communication suggests that when virtual messages are ambiguous they will be attributed according to how much an individual likes their communication partner (Friedman \& Currall, 2003). Therefore, relatively innocent messages may be misinterpreted as aggressive if the receiver holds an unfavourable view of the sender. This suggests that messages that appear ambiguous in text form should be avoided and, instead, the sender should make efforts to discuss the matter on the telephone or face-to-face, where there is less margin for misattribution.

\section{Summary}

There is very little research evidence on workplace cyberbullying and even less on how to prevent it. As research continues, identifying effective ways of preventing cyberbullying should be a priority. However, in the meantime, one strategy that has been used effectively by targets involves recording all the evidence of cyberbullying events and using this to report or deter the perpetrator (D’Cruz \& Noronha, 2013). Other suggestions include exercising control over how/when to respond to the perpetrator, and communicating ambiguous or complex subjects face-to-face or over the telephone.

Since we advocate conceptualising cyberbullying in the same manner as traditional bullying, frameworks developed to address the latter can guide intervention efforts. One prominent framework involves categorising intervention efforts as primary, secondary and tertiary (Hershcovis, Reich, \& Niven, 2015). Primary interventions seek to prevent bullying, secondary interventions aim to provide targets with coping resources and tertiary 
interventions purport to lessen the impact. This model can be used by practitioners to ensure there are processes in place to prevent, address and alleviate bullying and cyberbullying.

\section{Work Context of Cyberbullying}

D’Cruz and Noronha (2017c, forthcoming) point out that available insights into workplace cyberbullying come from conventional workplaces which are anchored in materiality.

Workplace interactions, usually marked by physical co-location of colleagues, could be faceto-face and virtual, entail verbal (oral and written) and non-verbal communication and occur synchronously and asynchronously, generally over the course of extended or long-term relationships. Employment in these workplaces is within the ambit of widely recognized standard and non-standard contracts, but is nonetheless geographically linked to a particular country and governed by national and international regulatory frameworks. Social protection and social dialogue further safeguard employee interests. Workplace bullying in conventional workplaces, which could be both traditional and virtual in form, unfolds against this backdrop.

The emergence of fully virtual workplaces such as online labour markets (OLMs; Lehdonvirta, Hjorth, Graham \& Barnard, 2015) implies a new context for workplace bullying where only online bullying is evidenced. D’Cruz and Noronha (2017a forthcoming; 2017c forthcoming) is the only study we could find on cyberbullying in OLMs. Their findings suggest some special nuances of workplace cyberbullying in this setting. First, as mentioned earlier, bullying here is exclusively virtual in form, in keeping with the immaterial character of the workplace which entails computer-mediated communication only. Second, though OLMs connect spatially dispersed strangers from across the globe via the roles of clients/buyers and freelancers/sellers engaged jointly on projects, the availability of identities on the site, usually verified by site administrators, eliminates anonymity. Even so, interactions on OLMs are exclusively virtual and mostly short-term, such that their mediated and fleeting nature lowers inhibitions and heightens detachment. Moreover, interactions unfold via written text and occur asynchronously unless both parties are logged in simultaneously. Nonetheless, interactions are restricted to the OLM itself since contact details of clients and freelancers are unavailable via the site unless both parties themselves choose to share these. Besides, interactions usually occur solely between the parties involved in a 
project, which most often is limited to two people, namely, the client and the freelancer. Hence, the question of bystanders in instances of cyberbullying rarely arises. Third, OLMs contain in-built monitoring and surveillance such that the generation and storage of digital footprints are automatic. Client and freelancer behaviour can be tracked and sanctioned. Fourth, reputation, represented as an ongoing assessment of professional standing and dealings and personal demeanour for clients, and calculated as an ongoing metric of professional capability and performance and personal etiquette for freelancers, is key to the selection process, and is critical for both client and, especially, freelancer success and continuity on the site. Not surprisingly, reputation has implications for targets' coping with cyberbullying.

D’Cruz and Noronha (2017a forthcoming; 2017c forthcoming) observed that, on the one hand, perpetrators take the risk of engaging in virtual abuse though they can be identified and sanctioned - this is despite the compromise of their profiles, success and tenure on the site. On the other hand, targets exercise caution about adopting counter aggressive positions to protect themselves, recognising that these acts adversely affect their reputation, success and continuity - they choose emotion-focused coping if they consider site-based redressal an unviable option.

\section{Summary}

The insights offered by D’Cruz and Noronha's (2017a forthcoming; 2017c forthcoming) research raise pointers for further inquiries: Why do perpetrators take the risk of engaging in cyberbullying acts on OLMs when they can leave digital footprints? What can OLMs do to support targets who do not meet the criteria for site-based redressal? What governance mechanisms are relevant for OLMs to ensure that they are dignified workplaces? In seeking answers to these issues, it must be noted that OLMs constitute a special type of workplace since they are not characterized by widely adopted standard and non-standard employment contracts and conventional regulatory frameworks and protection mechanisms. Instead, they operate beyond democratic charge, being invisible and borderless, with no link to the state and hence outside the purview of governments, legislations and unions (D’Cruz \& Noronha, 2016). Moreover, research across the spectrum of OLMs encompassing low-end micro-task sites, skilled and professional online workplaces and specialised, sophisticated, high-value digital spaces could provide even more detailed insights into the phenomenon of cyberbullying in virtual workplaces (D’Cruz \& Noronha, 2017a, forthcoming). 


\section{Conclusion}

On the $8^{\text {th }}$ December 2016, the New York Times published the headline 'Trump as Cyberbully in Chief? Twitter Attack on Union Boss Draws Fire'. The headline, combined with increasing research on the topic suggests that we are well-aware that cyberbullying is not a problem confined to young people. The purpose of this chapter was to consolidate the research conducted on workplace cyberbullying thus far, including findings on the nature of cyberbullying in organisations, as well as its prevalence, antecedents and impact. We take the view that cyberbullying is conceptually identical to traditional bullying, in the sense that it comprises aggressive, repeated and power-oriented behaviour. However, when bullying is conducted online, the unique contextual factors can produce a different experience for perpetrators, targets and bystanders. For example, a target will still be exposed to repeated abusive messages, but these messages would be available to see wherever the target is situated. In turn, these contextual factors may produce new perpetrators and risk groups, for instance two studies conducted on different continents both found that cyberbullying was experienced to a greater extent by supervisors, rather than non-supervisors.

Given that research on cyberbullying is still in the early phases, there exists numerous avenues for future research. These include, but should not be restricted to (1) investigating how the unique features of cyberbullying affect the experience for targets. (2) Determining the extent that traditional workplace bullying and cyberbullying overlap. (3) Identifying the organisational sectors and professional roles that are most at risk of cyberbullying. (4) Longitudinal investigation of the prevalence of cyberbullying and its relationship with health variables. (5) Identifying whether novel reasons exist why an individual may engage in cyberbullying, but not traditional bullying and vice versa. (6) Exploring the dynamics of cyberbullying across conventional and digital workplaces. (7) Finally, and perhaps most importantly, research should focus on the methods that work effectively to prevent and reduce cyberbullying at work. Technology will be an important tool as work, jobs and communication continue to evolve, but we need to use it without causing harm. 


\section{References}

Anderson, C., \& Galinsky, A. D. (2006). Power, optimism, and risk-taking. European Journal of Social Psychology, 36, 511-536.

Ang, R.P., \& Goh, D.H. (2010). Cyberbullying among adolescents: the role of affective and cognitive empathy, and gender. Child Psychiatry and Human Development, 41, 387-397.

Baruch, Y. (2005). Bullying on the net: Adverse behavior on e-mail and its impact. Information \& Management, 42(2), 361-371.

Bauman, S., \& Del Rio, A. (2006). Preservice teachers’ responses to bullying scenarios: Comparing physical, verbal and relational bullying. Journal of Education Psychology, 98(1), 219-231.

Bauman, S., \& Newman, M. L. (2013). Testing assumptions about cyberbullying: Perceived distress associated with acts of conventional and cyber bullying. Psychology of Violence, 3(1), 27-38.

Björkqvist, K, Lagerspetz, K. \& Kaukiainen, A. (1992). Do girls manipulate and boys fight? Developmental trends in regard to direct and indirect aggression. Aggressive Behavior, 18, 117-127.

Brinkley, I., Fauth, R., Mahdon, M., \& Theodoropoulou, S. (2009). Knowledge workers and knowledge work: A knowledge economy programme report. London: The Work Foundation.

Byron, K., \& Baldridge, D. (2005). Toward a model of nonverbal cues and emotion in email. In K. M. Weaver (Ed.), Academy of Management Best Papers Proceedings: OCIS B1- B6.

Cassidy, W., Faucher, C., \& Jackson, M. (2014). The dark side of the ivory tower: Cyberbullying of university faculty and teaching personnel. Alberta Journal of Educational Research, 60(2), 279-299.

Chekwa, C. \& Thomas, E. (2013). Workplace bullying: Is it a matter of growth? Journal of Diversity Management, 8, 45-50.

Clark, H. \& Brennan, S. (1991). Grounding in communication. In L. Resnick, J. Levine \& S. Teasley (Eds), Perspectives on socially shared cognition (pp. 127-149). Washington, DC: American Psychological Association.

Coyne, I., \& Farley, S. (in review). Cyberbullying within working contexts. In W. Cassidy, C. Faucher \& M. Jackson (Eds), Cyberbullying at University: A Cross-Jurisdictional, MultiDisciplinary Perspective. Routledge, Psychology Press, Taylor \& Francis Group. 
Coyne, I., Farley, S., Axtell, C., Sprigg, C., Best, L., \& Kwok, O. (2016). Understanding the relationship between experiencing workplace cyberbullying, employee mental strain and job satisfaction: a dysempowerment approach. The International Journal of Human Resource Management, 1-28.

Coyne, I., Gopaul, A-M., Campbell, M., Pankász, A., Garland, R., \& Cousans, F. (2017). Bystander responses to bullying at work: The role of mode, type and relationship to target. Journal of Business Ethics.

D’Cruz, P. (2015). Depersonalized bullying at work. New Delhi: Springer.

D’Cruz, P. (2016). Cyberbullying at Work: Experiences of Indian Employees. In Virtual Workers and the Global Labour Market. In J. Webster \& K. Randle (Eds), Dynamics of Virtual Work (pp. 239-259). Palgrave, Macmillan UK.

D'Cruz, P., \& Noronha, E. (2010). Protecting my interests: HRM and targets' coping with workplace bullying. The Qualitative Report, 15(3), 507-534.

D'Cruz, P., \& Noronha, E. (2011). The limits to workplace friendship: Managerialist HRM and bystander behaviour in the context of workplace bullying. Employee Relations, 33(3), 269-288.

D'Cruz, P., \& Noronha, E. (2013). Navigating the extended reach: Target experiences of cyberbullying at work. Information and Organization, 23(4), 324-343.

D'Cruz, P., \& Noronha, E. (2014). The interface between technology and customer cyberbullying: Evidence from India. Information and Organization, 24(3), 176-193.

D’Cruz, P., \& Noronha, E. (2015). Customer cyberbullying: The experiences of India's international-facing call centre agents. In S. Sahadev, K. Purani \& N. Malhotra (Eds.) Boundary spanning elements and the marketing function in organizations (pp. 9-32). London: Springer.

D’Cruz, P. And Noronha, E. (2016). Positives outweighing negatives: The experiences of Indian crowd sourced workers. Work Organization, Labour and Globalization, 10(1), 44-63.

D’Cruz, P. \& Noronha, E. (2017a, forthcoming). Target experiences of workplace bullying on online labour markets: Uncovering the nuances of resilience. Employee Relations.

D’Cruz, P. and Noronha, E. (2017b) “Workplace cyberbullying”, in Briken, K. et al (Eds), The new digital workplace: How new technologies revolutionize work. Palgrave, Macmillan Basingstoke. 
D’Cruz, P. \& Noronha, E. (2017c, forthcoming). Abuse on online labour markets: Targets' coping, power and control. Qualitative Research in Organizations and Management.

DeHue, F., Bolman, C., \& Völlink, T. (2008). Cyberbullying: Youngsters' experiences and parental perception. CyberPsychology \& Behavior, 11(2), 217-223.

Dooley, J. J., Pyżalski, J., \& Cross, D. (2009). Cyberbullying versus face-to-face bullying: A theoretical and conceptual review. Zeitschrift für Psychologie/Journal of Psychology, 217(4), 182-188.

Einarsen, S. (2000). Harassment and bullying at work: A review of the Scandinavian approach. Aggression and Violent Behavior, 5(4), 379-401.

Einarsen, S., Hoel, H., \& Notelaers, G. (2009). Measuring exposure to bullying and harassment at work: Validity, factor structure and psychometric properties of the Negative Acts Questionnaire-Revised. Work \& Stress, 23(1), 24-44.

Einarsen, S., Hoel, H., Zapf, D., \& Cooper, C. (2011). Bullying and Harrassment in the Workplace: Developments in Theory, Research and Practice. Second Edition. Boca Raton: CRC Press.

Escartín, J., Rodríguez-Carballeira, Á., Gómez-Benito, J., \& Zapf, D. (2010). Development and validation of the workplace bullying scale EAPA-T. International Journal of Clinical Health \& Psychology, 10, 519-539.

Eurostat. (2014). Mobile connection to the internet. Accessed from http://ec.europa.eu/eurostat/statistics-explained/index.php/Mobile_connection_to_internet on 20th October, 2016.

Eurostat. (2016). Social media - statistics on the use by enterprise. Accessed from http://ec.europa.eu/eurostat/statistics-explained/index.php/Social_media_statistics_on_the_use_by_enterprises on 20th October, 2016.

Farley, S. (2015). The measurement and impact of workplace cyberbullying. Unpublished $\mathrm{PhD}$ thesis, University of Sheffield, UK.

Farley, S., Coyne, I., Axtell, C., \& Sprigg, C. (2016). Design, development and validation of a workplace cyberbullying measure, the WCM. Work \& Stress, 30(4), 293-317.

Farley, S., Coyne, I., Sprigg, C., Axtell, C., \& Subramanian, G. (2015). Exploring the impact of workplace cyberbullying on trainee doctors. Medical Education, 49, 436-443 
Fevre, R., Lewis, D., Robinson, A., \& Jones, T. (2012). Trouble at work. London: Bloomsbury.

Fevre, R., Robinson, A., Lewis, D., \& Jones, T. (2013). The ill-treatment of employees with disabilities in British workplaces. Work, Employment and Society, 27(2), 288-307.

Ford, D. P. (2013). Virtual harassment: media characteristics' role in psychological health. Journal of Managerial Psychology, 28, 408-428.

Forssell, R. (2016). Exploring cyberbullying and face-to-face bullying in working lifePrevalence, targets and expressions. Computers in Human Behavior, 58, 454-460.

Friedman, R. A., \& Currall, S. C. (2003). Conflict Escalation: Dispute Exacerbating Elements of Email Communication. Human Relations, 56, 1325-1347.

Gardner, D., O’Driscoll, M., Cooper-Thomas, H. D., Roche, M., Bentley, T., Catley, B., Teo, S. T. T., \& Trenberth, L. (2016). Predictors of workplace bullying and cyber-bullying in New Zealand. International Journal of Environmental Research and Public Health, 13(5), 448462.

Gilson, L. L., Maynard, M. T., Young, N. C. J., Vartiainen, M., \& Hakonen, M. (2015). Virtual teams research 10 years, 10 themes, and 10 opportunities. Journal of Management, 41(5), 1313-1337.

Gradinger, P., Yanagida, T., Strohmeier, D., \& Spiel, C. (2016). Effectiveness and sustainability of the ViSC Social Competence Program to prevent cyberbullying and cybervictimization: Class and individual level moderators. Aggressive Behavior, 42(2), 181-193.

Hardaker, C. (2010). Trolling in asynchronous computer-mediated communication: From user discussions to academic definitions. Journal of Politeness Research. Language, Behaviour, Culture, 6(2), 215-242.

Heatherington, W., \& Coyne, I. (2014). Understanding individual experiences of cyberbullying encountered through work. International Journal of Organization Theory and Behavior, 17(2), 163-192.

Hershcovis, M. S. (2011). “Incivility, social undermining, bullying... oh my!”: A call to reconcile constructs within workplace aggression research. Journal of Organizational Behavior, 32, 499-519.

Hershcovis, M. S., Ogunfowora, B., Reich, T. C., \& Christie, A. M. (2017). Targeted workplace incivility: the roles of belongingness, embarrassment, and power. Journal of Organizational Behavior. DOI: 10.1002/job.2183 
Hershcovis, S. M., Reich, T. C., \& Niven, K. (2015). Workplace bullying: causes, consequences, and intervention strategies. SIOP White Paper Series, Society for Industrial and Organizational Psychology, UK, London.

Hershcovis, M. S., \& Reich, T. C. (2013). Integrating workplace aggression research: Relational, contextual, and method considerations. Journal of Organizational Behavior, 34(S1), S26-S42.

Hoel, H. (2013). Workplace Bullying in the United Kingdom. In The Japan Institute for Labour Policy and Training (Eds), Workplace Bullying and Harassment JILPT Report, 12, 61-76.

Hong, J. C., Chien-Hou, L., Hwang, M. Y., Hu, R. P., \& Chen, Y. L. (2014). Positive affect predicting worker psychological response to cyber-bullying in the high-tech industry in Northern Taiwan. Computers in Human Behavior, 30, 307-314

Huang, Y. Y., \& Chou, C. (2010). An analysis of multiple factors of cyberbullying among junior high school students in Taiwan. Computers in Human Behavior, 26(6), 1581-1590.

Johns, T., \& Gratton, L. (2013). The third wave of virtual work. Harvard Business Review, 91, 66-73.

Karasek, R. \& Theorell, T. (1990). Healthy Work: Stress, Productivity und the Reconstruction of Working Lge. New York: Basic Books.

Korczynski, M., \& Evans, C. (2013). Customer abuse to service workers: an analysis of its social creation within the service economy. Work, Employment \& Society, 27(5), 768-784.

Kowalski, R. M., Giumetti, G. W., Schroeder, A. N., \& Lattanner, M. R. (2014). Bullying in the digital age: A critical review and meta-analysis of cyberbullying research among youth. Psychological Bulletin, 140(4), 1073-1137.

Kowalski, R. M., \& Limber, S. P. (2007). Electronic bullying among middle school students. Journal of Adolescent Health, 41, 22-30.

Kowalski, R. M., Toth, A., \& Morgan, M. (2017). Bullying and cyberbullying in adulthood and the workplace. The Journal of Social Psychology, 1-18.

Langos, C. (2012). Cyberbullying: The challenge to define. Cyberpsychology, Behavior, and Social Networking, 15(6), $285 \mathrm{e} 289$.

Lehdonvirta, V., Hjorth, I., Graham, M., \& Barnard, H. (2015) Online Labour Markets and 
the Persistence of Personal Networks: Evidence From Workers in Southeast Asia. American Sociological Association Conference, 22-25 August, Chicago, USA.

Leymann, H., \& Gustafsson, A. (1996). Mobbing at work and the development of posttraumatic stress disorders. European Journal of Work and Organizational Psychology, 5(2), 251-275.

Li, Q., Smith, P. K., \& Cross, D. (2012). Research into cyberbullying. In Q. Li, D. Cross, and P. K. Smith (Eds.), Cyberbullying in the global playground (pp. 3-12), Wiley-Blackwell, Chichester.

Lutgen-Sandvik, P. (2006). Take this job and...: Quitting and other forms of resistance to workplace bullying. Communication Monographs, 73(4), 406-433.

Mainiero, L. A., \& Jones, K. J. (2013). Sexual harassment versus workplace romance: Social media spillover and textual harassment in the workplace. The Academy of Management Perspectives, 27(3), 187-203.

Menesini, E., Nocentini, A., \& Camodeca, M. (2013). Morality, values, traditional bullying, and cyberbullying in adolescence. British Journal of Developmental Psychology, 31, 1-14.

Minor, M. A., Smith, G. S., \& Brashen, H. (2013). Cyberbullying in higher education. Journal of Educational Research and Practice, 3(1), 15-21.

Mitchell, K. J., Jones, L. M., Turner, H. A., Shattuck, A., \& Wolak, J. (2016). The role of technology in peer harassment: Does it amplify harm for youth?. Psychology of Violence, 6(2), 193-204.

Mulder, R., Pouwelse, M., Lodewijkx, H. and Bolman, C. (2015), "Workplace mobbing and bystanders' helping behaviour towards victims: The role of gender, perceived responsibility and anticipated stigma by association”, International Journal of Psychology, 49(4), 304-312.

Nielsen, M. B., Hoel, H., Zapf, D., \& Einarsen, S. (2015). Exposure to Aggression in the Workplace. In S. Clarke, T.M. Probst, F. Guldenmund, \& J. Passmore (Eds.), The Wiley Blackwell Handbook of the Psychology of Occupational Safety and Workplace Health (205227). Chichester: Wiley Blackwell.

Nielsen, M. B., Matthiesen, S. B., \& Einarsen, S. (2010). The impact of methodological moderators on prevalence rates of workplace bullying. A meta-analysis. Journal of Occupational and Organizational Psychology, 83, 955-979.

Nielsen, M. B., Tangen, T., Idsoe, T., Matthiesen, S. B., \& Magerøy, N. (2015). Posttraumatic stress disorder as a consequence of bullying at work and at school. A literature review and meta-analysis. Aggression and Violent Behavior, 21, 17-24. 
Noronha, E., \& D'Cruz, P. (2013, January). Routine resistance: Limits to reclaiming power in the context of depersonalized bullying. In Academy of Management Proceedings (Vol. 2013, No. 1, p. 10346). Academy of Management.

Olweus, D. (2012). Comments on cyberbullying article: A rejoinder. European Journal of Developmental Psychology, 9(5), 559-568.

Olweus, D. (2013). School bullying: Development and some important challenges. Annual Review of Clinical Psychology, 9, 751-780.

Paull, M., Omari, M., \& Standen, P. (2012). When is a bystander not a bystander? A typology of the roles of bystanders in workplace bullying. Asia Pacific Journal of Human Resources, 50, 351-366.

Privitera, C., \& Campbell, M. A. (2009). Cyberbullying: The new face of workplace bullying?. CyberPsychology \& Behavior, 12, 395-400.

Reich, T. C., \& Hershcovis, M. S. (2015). Observing workplace incivility. Journal of Applied Psychology, 100(1), 203-215.

Salin, D (2003) Ways of explaining workplace bullying: a review of enabling, motivating and precipitating structures and processes in the work environment. Human Relations, 56, 12131232.

Salin, D., \& Hoel, H. (2013). Workplace bullying as a gendered phenomenon. Journal of Managerial Psychology, 28(3), 235-251.

Sims, R. L., \& Sun, P. (2012). Witnessing workplace bullying and the Chinese manufacturing employee. Journal of Managerial Psychology, 27(1), 9-26.

Skogstad, A., Torsheim, T., Einarsen, S., \& Hauge, L. J. (2011). Testing the work environment hypothesis of bullying on a group level of analysis: Psychosocial factors as precursors of observed workplace bullying. Applied Psychology, 60(3), 475-495.

Slonje, R., \& Smith, P. K. (2008). Cyberbullying: Another main type of bullying? Scandinavian Journal of Psychology 49, 147-154.

Slonje, R., Smith, P. K., \& Frisén, A. (2013). The nature of cyberbullying, and strategies for prevention. Computers in Human Behavior, 29(1), 26-32.

Smith, P. K. (2012a). Cyberbullying: Challenges and opportunities for a research program- 
A response to Olweus (2012). European Journal of Developmental Psychology, 9(5), 553558.

Smith, P. K. (2012b). Cyberbullying and cyber aggression. In S. R. Jimerson, A. B. Nickerson, M. J. Mayer, and M. J. Furlong (Eds.), Handbook of school violence and school safety: International research and practice. New York, NY: Routledge.

Smith P. K, del Barrio, C., \& Tokunaga, R. (2013). Definitions of bullying and cyberbullying: How useful are the terms? In S, Bauman, D, Cross, \& J, Walker (Eds) Principles of Cyberbullying Research: Definition, Measures, and Methods (pp. 29-40). Philadelphia, PA: Routledge.

Smith, P. K., Mahdavi, J., Carvalho, M., Fisher, S., Russell, S., \& Tippett, N. (2008). Cyberbullying: Its nature and impact in secondary school pupils. Journal of Child Psychology and Psychiatry, 49, 376-385.

Snyman, R., \& Loh, J. M. (2015). Cyberbullying at work: The mediating role of optimism between cyberbullying and job outcomes. Computers in Human Behavior, 53, 161-168.

Symantec. (2016). Norton Study Shows Online Harassment At Epidemic Proportions for Young New Zealand Women. Retrieved February $27^{\text {th }}$, 2017, from https://www.symantec.com/en/au/about/newsroom/press-releases/2016/symantec_0720_01

The Telegraph. (2015, September $25^{\text {th }}$ ). Facebook 'unfriending' can constitute workplace bullying, Australian tribunal finds. Retrieved May $5^{\text {th }}$, 2017, from http://www.telegraph.co.uk/news/worldnews/australiaandthepacific/australia/11890275/Face book-unfriending-can-constitute-workplace-bullying-Australian-tribunal-finds.html.

Tokunaga, R. S. (2010). Following you home from school: A critical review and synthesis of research on cyberbullying victimization. Computers in human behavior, 26(3), 277-287.

van Geel, M., Goemans, A., Toprak, F., \& Vedder, P. (2017). Which personality traits are related to traditional bullying and cyberbullying? A study with the Big Five, Dark Triad and sadism. Personality and Individual Differences, 106, 231-235.

Vandebosch, H., Simulioniene, R., Marczak, M., Vermeulen, A., \& Bonetti, L. (2013). The role of the media. In P.K. Smith, \& G. Steffgen (Eds.), Cyberbullying through the new media: Findings from an international network (108-118). Psychology Press: London and New York.

Vandebosch, H., \& Van Cleemput, K. (2008). Defining cyberbullying: A qualitative research into the perceptions of youngsters. CyberPsychology \& Behavior, 11(4), 499-503.

Varjas, K., Talley, J., Meyers, J., Parris, L., \& Cutts, H. (2010). High school students’ 
perceptions of motivations for cyberbullying: An exploratory study. Western Journal of Emergency Medicine, 3, 269-273.

Vranjes, I., Baillien, E., Vandebosch, H., Erreygers, S., \& De Witte, H. (2017). The dark side of working online: Towards a definition and an Emotion Reaction model of workplace cyberbullying. Computers in Human Behavior, 69, 324-334.

Wang, J., Iannotti, R. J., \& Nansel, T. R. (2009). School bullying among US adolescents: Physical, verbal, relational, and cyber. Journal of Adolescent Health, 45, 368-375.

West, B., Foster, M., Levin, A., Edmison, J., \& Robibero, D. (2014). Cyberbullying at Work: In Search of Effective Guidance. Laws, 3, 598-617.

Williams, K. R., \& Guerra, N. G. (2007). Prevalence and predictors of internet bullying. Journal of Adolescent Health, 41, 14-21.

Williford, A., Elledge, L. C., Boulton, A. J., DePaolis, K. J., Little, T. D., \& Salmivalli, C. (2013). Effects of the KiVa antibullying program on cyberbullying and cybervictimization frequency among Finnish youth. Journal of Clinical Child \& Adolescent Psychology, 42, 820-833.

Wood, S., Braeken, J., \& Niven, K. (2013). Discrimination and well-being in organizations: Testing the differential power and organizational justice theories of workplace aggression. Journal of Business Ethics, 115(3), 617-634.

Zapf, D., Escartín, J., Einarsen, S., Hoel, H., \& Vartia, M. (2011). Empirical findings on prevalence and risk groups of bullying in the workplace. In S. Einarsen, H. Hoel, D. Zapf, \& C. L. Cooper (Eds.), Bullying and emotional abuse in the workplace: International perspectives in research and practice (75-106). Boca Raton: CRC Press.

Zapf, D., Knorz, C., \& Kulla, M. (1996). On the relationship between mobbing factors, and job content, social work environment, and health outcomes. European Journal of Work and Organizational Psychology, 5(2), 215-237.

Zhang, S., \& Leidner, D. (2014, August). Workplace cyberbullying: The antecedents and consequences. Twentieth Americas Conference on Information Systems, Savannah, GA. 


\section{Tables}

Table 1: A description of three real-life cyberbullying cases

Case 1 (D’Cruz \& Noronha, 2013, p. 355): A participant who refused the romantic advances of a colleague found that when she was away from the office for a few days, the colleague hacked her office computer system which was left open for upgrading purposes. The colleague gathered personal information from her PC (personal computer) and was able to acquire her fiancé's contact details. He then proceeded to send the fiancé numerous anonymous emails and text messages over a period of several weeks which contained false information about the participant's character being morally loose in relation to men. After being informed about the messages by her fiancé, the participant guessed the sender's identity from her earlier rejection of his romantic advances.

Case 2 (Heatherington \& Coyne, 2014, p. 172): The work group of a participant based in the US (United States of America) pharmaceutical sector was reorganised, so she started reporting to a line manager located in another part of the country. The participant reported that computer-mediated messages with her line manager were cold from the start, which created a personality clash. She stated that a particularly difficult aspect of the situation was the sense that (because she was often able to work at home) she felt that her manager was crossing a boundary and that she should not have to tolerate bullying outside the physical confines of the workplace.

Case 3 (The Telegraph, 2015): The Telegraph newspaper reported on a workplace tribunal conducted by the Fair Work Commission in Australia, involving a dispute between two colleagues working in a real estate agency. Ms Roberts (the target) had complained that her properties were not being adequately advertised in the store window, which led to a dispute with the perpetrator (a sales administrator). Ms Roberts later checked if the sales administrator had commented on the incident on social media, only to find that she had been 'unfriended' by the perpetrator. The tribunal ruled that this action evidenced a lack of emotional maturity and was indicative of unreasonable behaviour. They also ruled that workplace bullying had occurred, although it was not the unfriending that led to this ruling, but a pattern of hostile behaviour over a period of two years. 
Table 2: Workplace cyberbullying prevalence compared with traditional bullying prevalence

\begin{tabular}{|c|c|c|c|c|c|c|}
\hline \multirow[b]{2}{*}{ Study } & \multirow[b]{2}{*}{$\begin{array}{l}\text { No. of } \\
\text { respondents }\end{array}$} & \multirow[b]{2}{*}{ Country } & \multicolumn{2}{|c|}{ Cyberbullying Measurement } & \multicolumn{2}{|c|}{ Traditional Bullying co-measurement } \\
\hline & & & $\begin{array}{l}\text { Self-labelling with } \\
\text { definition }\end{array}$ & $\begin{array}{c}\text { Behavioural } \\
\text { experience method }\end{array}$ & $\begin{array}{l}\text { Self-labelling with } \\
\text { definition }\end{array}$ & $\begin{array}{c}\text { Behavioural } \\
\text { experience method }\end{array}$ \\
\hline Baruch (2005) & 649 & UK & $9.2 \%$ & - & $13.6 \% *$ & - \\
\hline Cassidy et al. (2014) & 121 & Canada & $17 \%$ & - & - & - \\
\hline Coyne et al. (2016) & 120 & UK & - & $13.6 \%$ & - & $19.7 \%$ \\
\hline Forssell (2016) & 3,371 & Sweden & $0.7 \%$ & $9.7 \%$ & $3.5 \%$ & - \\
\hline Gardner et al. (2016) & 826 & New Zealand & - & $2.8 \%$ & $18.5 \% *$ & $15 \%$ \\
\hline Minor et al. (2013) & 346 & USA & $33.8 \%$ & - & - & - \\
\hline $\begin{array}{l}\text { Privitera \& Campbell } \\
\text { (2009) }\end{array}$ & 103 & Australia & - & $10.7 \%$ & $31.1 \% *$ & $23.3 \%$ \\
\hline
\end{tabular}

Table Notes:

1. * Denotes studies where the definition used covers both traditional bullying and cyberbullying.

2. Figures reported in the behavioural experience column refer to the percentage of respondents who have experience at least 1 act per week, apart from where the "symbol has been used, which indicates that respondents were classified on the basis of experiencing 2 acts per week.

3. Some studies used a response scale when assessing self-labelled victimisation to obtain categories of victims (e.g. bullied now and then, bullied weekly or bullied daily), the figures reported here refer to the percentage of all respondents who stated they were bullied, regardless of the time frame. 


\section{List of chapters across the volumes for cross-references}

\section{Volume 1 section A}

The hallmarks of workplace bullying, emotional abuse and harassment

Workplace bullying in the larger social context: A function of our times

The presence of workplace bullying and harassment worldwide

Theoretical frameworks that explain workplace bullying

Workplace bullying and the polemic of subjectivity and intent

The relevance of depersonalized and institutional bullying in the contemporary workplace

Ethical Challenges and Workplace Bullying and Harassment: Creating Ethical Awareness and Sensitivity.

\section{Volume 2 section A}

The contribution of organizational factors to workplace bullying, emotional abuse and harassment

The contested terrain of power in workplace bullying, emotional abuse and harassment

The role of personality in workplace bullying research

Workplace bullying and mental health

Health consequences of workplace bullying: Physiological response and sleep

The moderating effects of coping mechanisms and resources in the context of workplace bullying, emotional abuse and harassment Long-term consequences of workplace bullying, emotional abuse and harassment for organizations and society

Surviving workplace bullying, emotional abuse and harassment

Upwards bullying: What we can learn about workplace bullying 


\section{Volume 2 section B}

Targets of Workplace Bullying and Mistreatment: Helpless Victims or Active Provocateurs? Me? A Bully?

The role and impact of leaders on workplace bullying, emotional abuse and harassment

The role of bystanders in workplace bullying

The significant others of victims of bullying, emotional abuse and harassment at work

Human resources as an important actor in workplace bullying situations: Where we have been and where we should go

\section{Volume 3 Section A}

Workplace bullying policies: A review of best practices and research on effectiveness

Addressing workplace bullying: the role of training

Managing workplace bullying complaints: Conceptual influences and effects of conceptual factors

Complaint investigation in cases of workplace bullying, emotional abuse and harassment

Diagnosis and treatment: Repairing injuries caused by workplace bullying

Worker representation and advocacy

Regulation and legislation

Alternative dispute resolution and mediation

\section{Vol 3 section B}

Gender and workplace bullying

Age and workplace bullying 
Volume 4 Section A

Ostracism in the workplace

Customer abuse 